\title{
Efeitos dos glicosaminoglicanos e sulfato de condroitina A sobre a cartilagem articular normal e com doença articular degenerativa em cães
}

\author{
[Glycosaminoglycans and chondroitin sulphate " $A$ ” effects on normal and osteoarthritic \\ articular cartilage in $\operatorname{dog} s]$
}

\author{
N.T. Vieira ${ }^{1}$, E.G. Melo $^{2 *}$, C.M.F. Rezende ${ }^{2}$, M.G. Gomes ${ }^{1}$, F.M.C. Caldeira ${ }^{1}$, M.C. Jesus ${ }^{3}$ \\ ${ }^{1}$ Aluno de pós-graduação - EV-UFMG - Belo Horizonte, MG \\ ${ }^{2}$ Escola de Veterinária - UFMG - Belo Horizonte, MG \\ Caixa Postal 567 \\ 30123-970 - Belo Horizonte, MG \\ ${ }^{3}$ Aluno de graduação - EV-UFMG - Belo Horizonte, MG
}

\begin{abstract}
RESUMO
Avaliaram-se os efeitos dos precursores dos glicosaminoglicanos (GAG) e do sulfato de condroitina A (SC) sobre a histomorfometria da cartilagem articular normal ou de cartilagem de cães com doença articular degenerativa (DAD) experimental. Os grupos experimentais constituíram-se de animais com articulação direita normal, que não foi submetida a procedimento cirúrgico, e com articulação esquerda osteoartrótica e que foi submetida à intervenção cirúrgica. Os grupos foram subdivididos em animais com articulação não tratada e tratada, portanto: normais $(\mathrm{N}) \quad(\mathrm{n}=5)$, NGAG $(\mathrm{n}=5)$ e NSC $(\mathrm{n}=4)$; e osteoartróticos (O) $(n=5)$, OGAG (n=5) e OSC $(n=4)$. Secções de cartilagens do fêmur, da tíbia e da patela foram utilizadas neste estudo. Nos normais (N, NGAG e NSC), não se encontraram lesões que caracterizassem a DAD, embora tenha havido diminuição na celularidade nos de NGAG e NSC, em relação a N. Foram observadas alterações em graus variáveis entre os grupos osteoartróticos. Houve redução acentuada dos condrócitos no grupo $\mathrm{O}$ em comparação aos normais enquanto os grupos osteoartróticos tratados apresentaram celularidade semelhante aos normais tratados. Estes resultados foram confirmados pela análise do índice de proporção (IP), que se mostrou elevado em $\mathrm{O}$, indicando menor síntese de proteoglicanos. Não houve diferença significativa entre os IPs dos grupos osteoartróticos tratados (OGAG, OSC) apesar do comportamento distinto do OSC ao assemelhar-se aos grupos N e NSC. Estes resultados sugeriram que o SC agiu na cartilagem osteoartrótica de maneira mais eficaz, reduzindo a perda de proteoglicanos e estimulando a viabilidade celular e a atividade metabólica.
\end{abstract}

Palavras-chave: cão, doença articular degenerativa, precursores de glicosaminoglicanos, sulfato de condroitina, cartilagem articular

\begin{abstract}
The effects of precursors of glycosaminoglycans (GAG) and chondroitin sulphate $A(C S)$ on the histomorphometry of normal articular cartilage and with experimental degenerative joint disease (DJD) in dogs were evaluated. The groups were constituted as follows: normal joints were not undergone to the surgical procedure and left osteoarthritics that suffered surgical intervention. These were then distributed into joints that did not receive drug treatment and those that received: normal $(N)(n=5) ; N G A G(n=$ 5), and NCS $(n=4)$; and osteoarthritics: $O(n=5) ; O G A G(n=5)$; and OCS $(n=4)$. Cartilage sections of the femur, tibia, and patella were used in this study. In normal groups (N, NGAG, and NCS) no lesions were found that could characterize DJD, although the cellularity was shown to be slightly diminished in NGAG and NCS, in relation to N. Characteristic DJD disorders were identified in variable degrees among osteoarthritic groups and were more severe in $O$. There was marked reduction of the number of
\end{abstract}

Recebido em 29 de julho de 2009

Aceito em 10 de agosto de 2010

*Autor para correspondência (corresponding author)

E-mail: eliane@vet.ufmg.br 
chondrocytes in group $O$, as compared to the normal groups, while treated osteoathritic groups showed similar cellularity to that of normal groups. These results were supported by the analysis of the index of proportion (IP), which was high in $O$, indicating less synthesis of proteoglycans. These results suggest that chondroitin A sulphate acted on osteoarthritic cartilage in a more efficient way than glycosaminoglycan precursors, reducing the loss of proteoglycans caused by the degenerative process, stimulating cellular viability and metabolic activity.

Keywords: dog, degenerative joint disease, glycosaminoglycan precursors, chondroitin sulphate, articular cartilage

\section{INTRODUÇÃO}

A doença articular degenerativa (DAD) ou osteoartrose é uma enfermidade crônica progressiva, caracterizada por alterações degenerativas da articulação e de estruturas adjacentes, com perda significativa de seus componentes (Bobinac et al., 2003; Chan et al., 2005; Lorenz e Richter, 2006; Simon e Jackson, 2006; Laadhar et al., 2007).

Os tratamentos preconizados para osteoartrose, na prática clínica, têm evidenciado que o emprego de fármacos convencionais restringe-se a uma ação conservativa, encorajando, dessa forma, a procura por outros tratamentos que controlem as alterações geradas com a progressão da osteoartrose, e que possibilitem a recuperação da constituição da matriz extracelular nessa enfermidade.

Na medicina veterinária, é intensa a utilização de agentes condroprotetores ou drogas modificadoras da doença articular degenerativa (DMDAD) como tratamento complementar da DAD, embora ainda necessite de evidências quanto ao mecanismo de ação e eficácia.

O objetivo deste estudo foi avaliar o efeito dos precursores de glicosaminoglicanos e do sulfato de condroitina A sobre a morfologia da cartilagem articular normal e com osteoartrose experimental em cães.

\section{MATERIAL E MÉTODOS}

Este estudo é parte do trabalho "Precursores de glicosaminoglicanos e sulfato de condroitina A no tratamento da doença articular degenerativa em cães" aprovado pelo Comitê de Ética em Experimentação Animal sob o n ${ }^{\circ}$ 14/2002.

Utilizaram-se 14 cães de ambos os sexos, sem raça definida, pesando entre 18 e $25 \mathrm{~kg}$, submetidos à avaliação clínica e laboratorial prévia (pesquisa de leishmaniose, hemoparasitas e hemograma). Como critério de inclusão definitiva dos animais, também foram realizadas radiografias bilaterais das articulações femorotibiopatelares (FTP) direita e esquerda, nas incidências craniocaudal e mediolateral, para a constatação da normalidade nessas articulações.

Os animais foram encaminhados para a avaliação artroscópica com subsequente secção do ligamento cruzado cranial (LCCr) por essa mesma via, com auxílio de uma tesoura artroscópica. Após 21 dias, foram encaminhados e preparados para novo exame artroscópico. Após visualização e avaliação das estruturas articulares, conforme realizado na primeira artroscopia, executou-se uma artrotomia e substituição do LCCr segundo a técnica de Schawalder (1989). Em todos os animais foi empregada a Muleta de Thomas, modificada, por 15 dias.

Após substituição do LCCr esquerdo, as articulações FTP foram distribuídas em seis grupos experimentais. Nos animais de grupo I normal (N) a articulação FTP direita não submetida a procedimentos terapêutico e cirúrgico $(\mathrm{n}=5)$; nos do grupo II (NGAG), a articulação FTP direita não foi submetida a procedimento cirúrgico e foi tratada com precursores de glicosaminoglicanos (Osteocart Plus - Labyes) (dois comprimidos de $70 \mathrm{mg} / \mathrm{dia}$, por via oral, durante 30 dias $)(n=5)$; nos do grupo III (NSC), a articulação FTP direita não foi submetida a procedimento cirúrgico e foi tratada com sulfato de condroitina (D.M.P. - Labyes) $(3 \mathrm{mg} / \mathrm{kg}$, via intramuscular a cada três dias durante 30 dias e a cada quatro dias durante os 60 dias subsequentes) $(n=4)$; nos do grupo IV osteoartrótico (O); a articulação FTP esquerda foi submetida a procedimentos cirúrgicos (ruptura e substituição do LCCr) e não foi tratada 
$(n=5)$; nos do grupo V (OGAG); a articulação FTP esquerda submetida a procedimentos cirúrgicos (ruptura e substituição do LCCr) e tratada com precursores de glicosaminoclicanos (dois comprimidos de $70 \mathrm{mg} / \mathrm{dia}$, por via oral, durante 30 dias) $(\mathrm{n}=5)$; e nos do grupo VI (OSC); a articulação FTP esquerda foi submetida a procedimentos cirúrgicos (ruptura e substituição do LCCr) e tratada com sulfato de condroitina A $(3 \mathrm{mg} / \mathrm{kg}$, via intramuscular a cada três dias durante 30 dias e a cada quatro dias durante os 60 dias subsequentes) $(n=5)$.

Os protocolos utilizados neste experimento seguiram a posologia recomendada pelo fabricante. Ao final dos 90 dias, os cães foram sacrificados e submetidos ao exame pós mortem e à colheita de material para exame macroscópico e histológico de ambas as articulações FTP.

Amostras de fêmur, tíbia e patela com osso subcondral foram extraídas da porção articular de cada osso e fixadas em paraformaldeído neutro tamponado a $4 \%$ por, pelo menos, 60 dias. Com a utilização de serra linear, foram realizadas secções transversais em relação ao eixo maior do fêmur, desde o sulco patelar até a porção condilar. Em relação à tíbia, foram feitas secções longitudinais do platô tibial, com auxílio de serra circular, seguindo orientação craniocaudal em relação ao eixo maior do osso. Essas amostras iniciaram a descalcificação em solução fosfato de EDTA a $10 \%$ mantido à temperatura ambiente durante 240 dias. A descalcificação foi confirmada pela ausência de radiopacidade demonstrada pela radiografia e ausência de resistência ao corte com lâmina para microtomia.

Após pelo menos 90 dias na solução descalcificadora, os segmentos obtidos do fêmur foram divididos em porção medial e lateral. De cada fragmento condilar foram extraídos, pelo menos, quatro fragmentos, também com auxílio de lâmina para microtomia, os quais seguiram orientação de corte craniocaudal em relação ao eixo maior do osso. Quatro meses após o início da descalcificação, as amostras da patela foram divididas transversalmente ao seu eixo maior, com auxilio de lâmina para microtomia. Após a descalcificação, todos os fragmentos foram processados, incluídos em parafina e corados pela hematoxilina e eosina (HE), para avaliação morfológica e da celularidade das cartilagens articulares.

A análise morfométrica constou da contagem do número de condrócitos, em secções coradas pela HE, e quantificação do conteúdo de proteoglicanos, em secções coradas pela safranina O-fast green. A celularidade foi determinada pela contagem do número de células com objetiva de 40 em 24 campos/secção em 25 secções/grupo da cartilagem articular do fêmur, da tíbia e da patela, totalizando 600 campos/grupo. O número de campos em cada secção foi determinado pela técnica de estudo da variação da instabilidade de valores médios em relação à amostra que os originou. Em uma lâmina representativa de cada grupo experimental, foi determinado o número de células em 48 campos. A seguir, essa amostra de 48 campos foi dividida em quatro com valores sorteados ao acaso. Foram determinados a média, o desvio-padrão e o coeficiente de variação da variável estudada em 4, 8, 12, 16, 20, 24, 28, 32, 36, 40, 44 e 48 campos. Após verificar que o desvio-padrão e o coeficiente de variação se estabilizavam em torno de 24 campos, este valor foi adotado para se determinar o número de campos para a quantificação celular.

A mensuração do conteúdo de proteoglicanos foi feita por meio da técnica de coloração pela Safranina $\mathrm{O}$, em que se mediram, com o auxílio de ocular micrométrica, a altura da cartilagem e a quantificação da coloração total e da coloração positiva a safranina. Para isso mediu-se, em três pontos diferentes, a altura total da cartilagem articular, desde a tide mark até a porção mais apical da camada superficial. À média das três medidas aplicou-se um fator de correção, obtido com o auxílio de lâmina micrométrica. Calculouse, então, o índice de proporção (IP) entre a altura total e a dos proteoglicanos, segundo Melo et al. (2008):

$$
\mathrm{IP}=\frac{\text { Altura total }- \text { Altura Corada }}{\text { Altura total }}
$$

O delineamento experimental foi o inteiramente ao acaso. Os dados morfométricos das variáveis contagem celular e índice de proporcionalidade do conteúdo de proteoglicanos foram testados quanto à distribuição normal. As médias foram submetidas à análise de variância, e, para 
comparação de média, aplicou-se o teste SNK. A correlação entre elas foi determinada pelo teste de Pearson.

\section{RESULTADOS E DISCUSSÃO}

O modelo utilizado de ruptura do $\mathrm{LCCr}$ para a indução da DAD permitiu avaliar as alterações morfológicas comuns a esta patologia, já comprovado por Marijnissen et al. (2002); Biasi et al. (2005); Gonçalves et al. (2008) e Melo et al. (2008). O desenvolvimento e a progressão da DAD ocorreram devido à instabilidade articular, que alterou a distribuição de peso sobre a articulação (Romano et al, 2006; Glasson et al., 2007; Herzog e Longino, 2007). Segundo Gonçalves et al. (2008) e Melo et al. (2008), houve dificuldades quanto à diferenciação entre os tratamentos, uma vez que empregaram a mesma metodologia.

A cartilagem articular dos membros que não foi submetida a procedimento cirúrgico, grupos $\mathrm{N}$, NGAG, NSC, apresentou características histológicas semelhantes entre si, independente do tratamento ao qual foram submetidas (Fig. 2A). Não se observaram, nesses grupos, alterações que sugerissem estágios iniciais da DAD. Observou-se diferenciação limítrofe entre as camadas e visualizaram-se, com perfeição, as zonas superficial, média, profunda e calcificada, aspecto este que também auxilia na caracterização da cartilagem articular normal (Junqueira e Carneiro, 1999).

Verificou-se em todas as cartilagens articulares zona superficial regular (Fig. 2A), com monocamada de condrócitos basofílicos e fusiformes, assemelhando-se a fibroblastos, alinhados paralelamente à superfície articular. Nas regiões próximas às áreas de inserção dos tendões e dos ligamentos, a camada superficial também assumiu essas características, porém chegando a formar três a quatro camadas de células. Os condrócitos desta camada apresentaram-se separados entre si por discreta quantidade de matriz extracelular. Nas extremidades da superfície articular, observou-se a presença de grupos isógenos isolados (clones), não representativos de lesões à camada superficial, uma vez que a matriz circunjacente não apresentou alterações de DAD.
$\mathrm{Na}$ camada média, foram verificados poucos clones dispersos entre si e sem lesões próximas, não sendo possível correlacioná-los novamente com a presença de lesões decorrentes de DAD. Os condrócitos apresentaram-se arredondados, basofílicos com matriz interterritorial e tendendo a se orientar em colunas na região de transição com a camada profunda. Na camada profunda, essas células mantiveram a forma arredondada e apresentaram-se dispostos em colunas. A matriz interterritorial fortemente basofílica (Fig. 2A) sugeriu maiores quantidades de proteoglicanos. A presença de poucas áreas de fibrilação e raros grupos celulares isógenos, como os observados nas camadas superficial e média, são achados também encontrados em cartilagens normais decorrentes de indução mecânica, não sendo associadas à DAD (Fernandes et al., 1998; Pritzker et al., 2006).

Subjacente à camada profunda, a tide mark estava bastante evidente e íntegra em todas as amostras analisadas. A camada calcificada não apresentou alterações que estariam associadas à presença de DAD. Portanto, os resultados encontrados para a morfologia estão compatíveis com os descritos para cartilagem normal por Fernandes et al. (1998), Gannon e Sekoloff (1999), Lorenz e Richter (2006) e Pritzker et al., (2006).

A cartilagem articular, submetida aos procedimentos de desestabilização e substituição do LCCr, apresentou alterações morfológicas típicas de DAD, já descritas na literatura por Biasi et al. (2005); Pritzker et al. (2006); Gonçalves et al. (2008) e Melo et al. (2008).

No grupo $\mathrm{O}$, foram encontradas alterações principalmente nas camadas superficial e média. $\mathrm{Na}$ primeira, as lesões variaram de moderadas a graves e predominaram irregularidades na superfície, edema acentuado e presença de fibrilação. A separação das fibrilas de colágeno muitas vezes culminou em fissuras transversais que atingiram a camada média. Foram constatadas lesões características de degeneração, como a evidente necrose dos condrócitos (Fig. 2B, 2C e 3C) e presença de áreas multifocais sem camada superficial, diferente do descrito para esta zona nos grupos N, NGAG e NSC, já observados por Gannon e Sekoloff (1999), Kleeman et al. (2005); Pritzker et al. (2006); Laadhar, et al. (2007). 
As alterações degenerativas também estenderamse à camada média, sendo observados edema difuso, fibrilação e perda de basofilia (Fig. 2BD). Estas alterações confirmam a presença de DAD. Achados similares também foram descritos por Gannon e Sekoloff (1999); Bobinac et al. (2003); Pritzker et al. (2006) e Simon e Jackson (2006) e Gonçalves et al. (2008).

Foi observada presença de tecido fibroso disposto paralelamente e aderido à cartilagem articular, principalmente nos fragmentos de fêmur medial e de patela. As áreas com pânus apresentaram-se subjacentes a regiões de hipocelularidade e de condrócitos necróticos (Fig. 2C e 3C), assim como descrito por Gannon e Sekoloff (1999); Yuan et al. (2004) e Melo et al., 2008.

Nas áreas com lesões mais acentuadas de DAD, observou-se a presença de clones (Fig. 3A e 3D) com grande número de condrócitos organizados, sugerindo tentativa de reparo à perda celular. Kleeman et al. (2005) também associaram o aparecimento dos clones e de outras lesões, como fissuras, erosões (Fig. 2B) e flaps (Fig. 3B), a estágios mais avançados da DAD. O comportamento aberrante dos condrócitos na DAD, segundo Goldring (2006), é caracterizado ainda pelo aparecimento de fibrilações (Fig. 2D) e de alterações na quantidade, distribuição ou composição dos proteoglicanos da matriz, como constatado no presente estudo.

No grupo OGAG, a zona superficial da cartilagem articular apresentou-se com frequentes irregularidades, três a quatro camadas de células de fusiformes a arredondadas, basofílicas com aparente redução do tamanho celular, se comparada à dos grupos normais. Lesões semelhantes foram encontradas em camundongos e indicaram provável atividade proliferativa, que pode ser atribuída ao tratamento com precursores de glicosaminoglicanos (Fenton et al., 2000a,b; Varghese et al., 2007). Irregularidades na superfície articular, edema, fibrilação e necrose de condrócitos foram lesões também evidenciadas no grupo OGAG, contudo menos intensas do que as observadas no grupo osteoartrótico. Na maioria das vezes, não foi possível individualizar as camadas superficial e média, devido à homogeneidade dos condrócitos.
Na camada média, aspecto marcante foi a proliferação de condrócitos, com formação de clones (Fig.2C, 3A e 3B). Estes agregaram grande número de células com pouca matriz interterritorial entre si em áreas multifocais, dispostas adjacentes a células inviáveis ou a áreas de necrose. Os condrócitos na camada média apresentaram citoplasma amplo e bastante granulado, com núcleo vesiculoso de cromatina frouxa, achados que sugeriram incremento na atividade celular. A perda de basofilia da matriz interterritorial, observada nas camadas média e profunda, foi menos evidente do que no grupo $\mathrm{O}$.

As características morfológicas da cartilagem articular, no grupo OSC, foram menos marcantes de DAD do que as observadas no grupo OGAG. Lesões degenerativas como edema, fibrilação, necrose, pânus e hipercelularidade (Fig. 3D) foram também verificadas, entretanto, mais discretas e menos extensas. As células estavam distribuídas de forma difusa e apresentaram-se menores, contendo núcleo discretamente mais condensado. Houve perda discreta da basofilia da matriz extracelular. Estes achados assemelhamse aos de Melo et al. (2008), que também empregaram o sulfato de condroitina no tratamento da DAD.

As lesões histológicas dos grupos OGAG e OSC assemelharam-se às encontradas nas cartilagens do grupo $\mathrm{O}$ sendo, no entanto, de caráter menos grave, principalmente no OSC. A comparação entre as cartilagens articulares nos grupos osteoartróticos tratados indicaram diferença no padrão de proliferação celular. Estes resultados foram posteriormente confirmados pela análise morfométrica (Tab. 1). Semelhantes foram as alterações da DAD relatadas por Marijnissen et al. (2002); Biasi et al., (2005); Lorenz e Richter (2006); Pritzker et al. (2006) e Melo et al. (2008).

Nas camadas profunda e calcificada, não foram observadas alterações relacionadas a DAD, sugerindo que a substituição do $\mathrm{LCCr}$ e/ou o tempo de avaliação dos grupos não permitiram desenvolver lesões osteoartróticas mais acentuadas nessas camadas. 

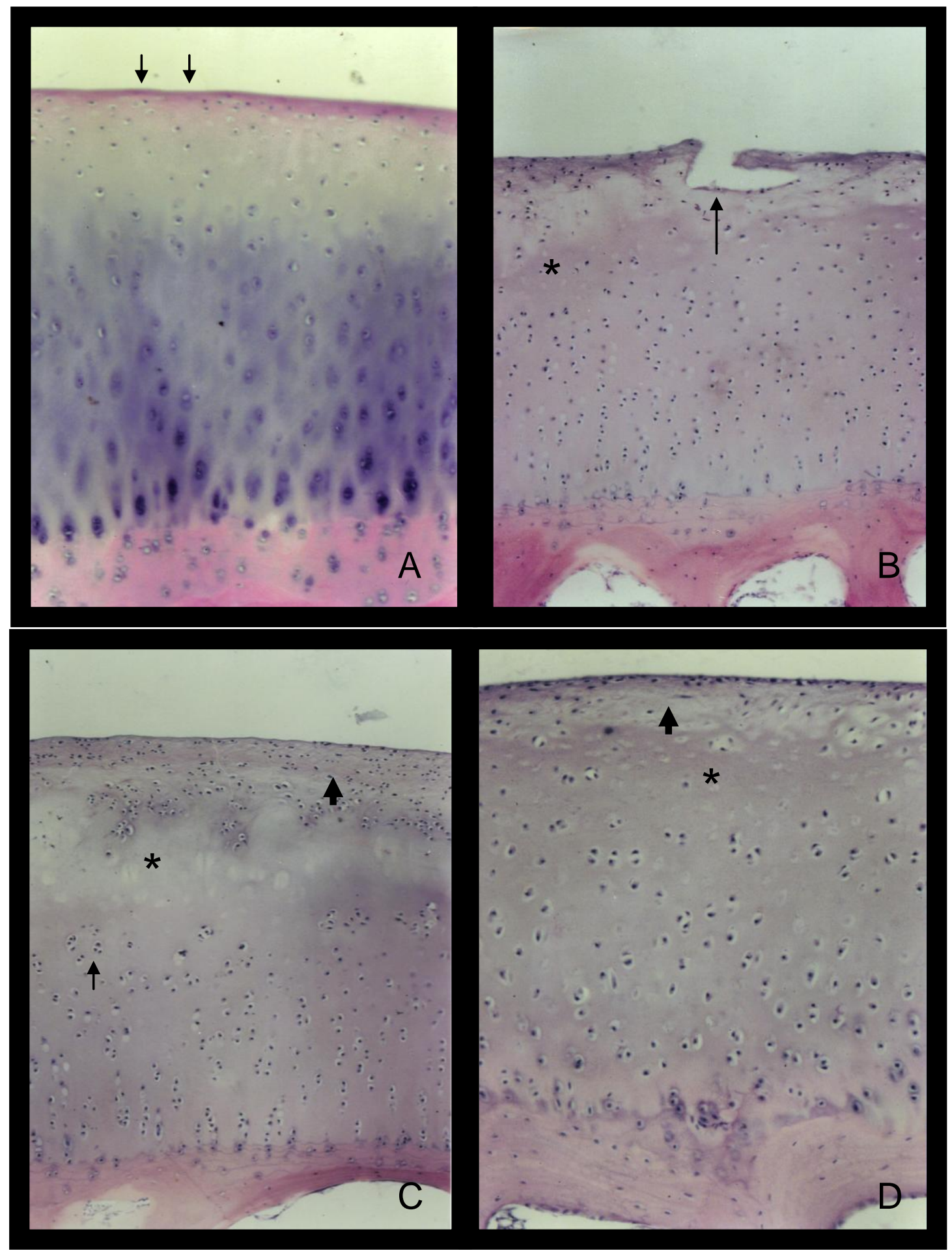

Figura 1. Fotomicrografias de cartilagens articulares de fêmur de cães. HE. A) grupo normal: regularidade da superfície articular (setas finas), ME intensamente basofílica, 135x; B-D) grupo osteoartrótico: redução da basofilia da ME; B) cartilagem apresentando áreas de erosão (seta) e de necrose (*), 135x; C) pânus (seta), necrose (*) e clones (seta fina); D) área de fibrilação e edema (seta), 189,4x. 

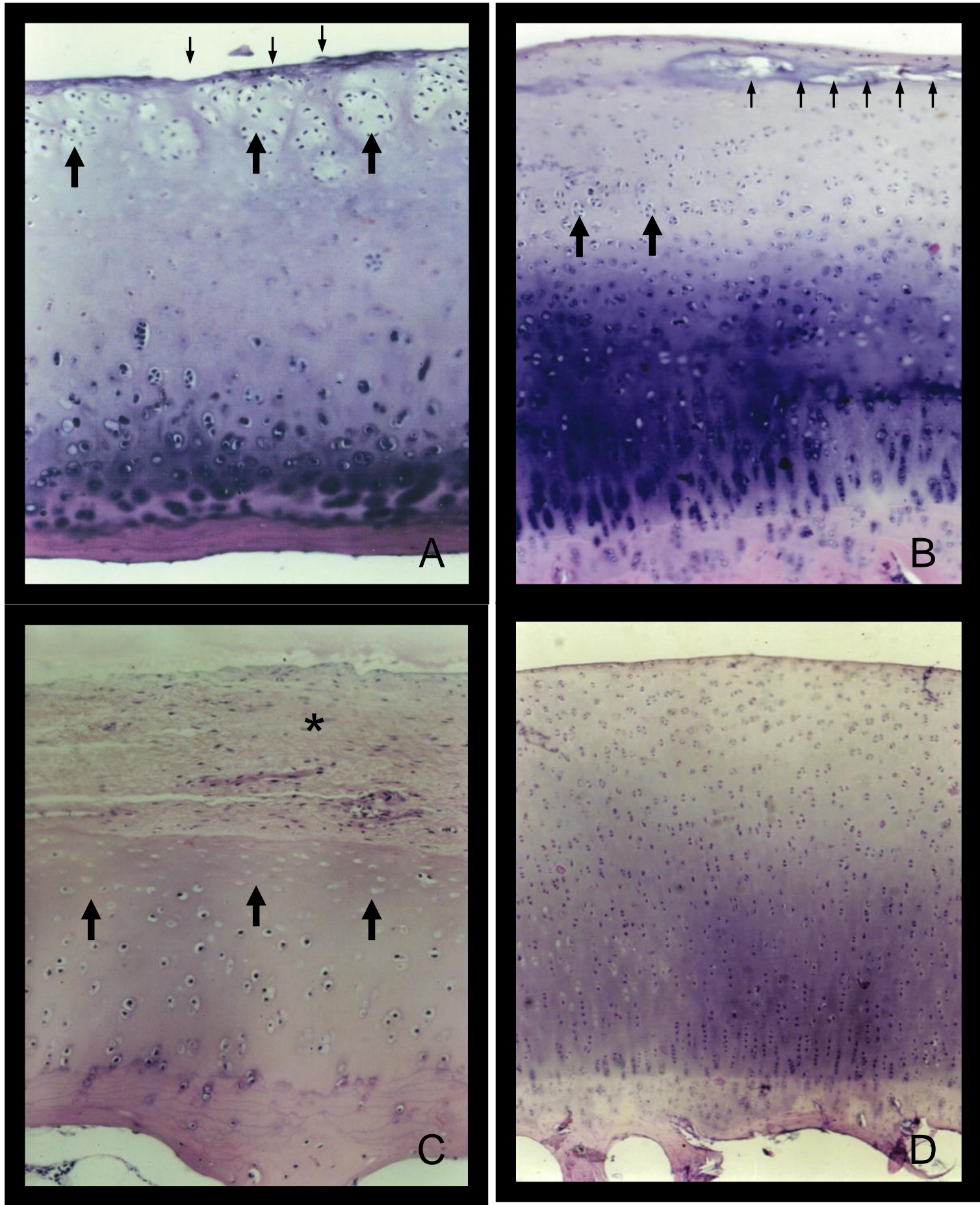

Figura 2. Fotomicrografias de cartilagens articulares de cães. HE. A-C) grupo osteoartrótico tratado com precursores de glicosaminoclicanos; A) fêmur: irregularidade da superfície articular (setas finas), clones e aumento multifocal da celularidade (seta). 75x; B) patela: fissura (seta fina) e clones (seta), 107,1x; C) fêmur: pânus (*) e necrose (seta), 171,4x; D) patela: grupo osteortrótico, tratado com sulfato de condroitina, aumento de celularidade, $75 x$. 
A celularidade oscilou entre os grupos experimentais, sendo observado maior número de condrócitos no grupo normal, se comparado aos normais tratados (NGAG e NSC) e aos osteoartróticos (O, OGAG e OSC). A diferença significativa no número de células entre os grupos normais e os normais tratados não foi perceptível à avaliação morfológica, uma vez que a cartilagem articular apresentou características semelhantes à normalidade. Ao se considerar a menor contagem de células nos grupos NGAG e NSC em relação ao N (Tab. 1), pode-se sugerir que os precursores de glicosaminoglicanos e o sulfato de condroitina A atuem no metabolismo dos condrócitos, reduzindo a capacidade proliferativa natural dessas células. Provavelmente, essa ação na celularidade foi similar entre os dois fármacos, visto não haver diferença significativa entre ambos. Semelhante também foi o número de condrócitos dos grupos normais tratados em relação aos osteoartróticos tratados. Estes resultados demonstraram que os precursores de glicosaminoglicanos e o sulfato de condroitina A exerceram ações também na cartilagem osteoartrótica, favorecendo a atividade reparativa frente às perdas ocorridas por necrose $\mathrm{e}$ apoptose, reduzindo-as de forma semelhante ao que foi descrito por Gomes (2006).

Tabela 1. Valores médios e desvios-padrão do número de células em cartilagens articulares normais e osteoartróticas de cães tratados ou não com precursores de glicosaminoglicanos e sulfato de condroitina A

\begin{tabular}{ll}
\hline Grupos & Número de células \\
\hline $\mathrm{N}$ & $118,5 \pm 3,3 \mathrm{a}$ \\
NGAG & $100,8 \pm 5,04 \mathrm{~b}$ \\
$\mathrm{NSC}$ & $94,58 \pm 5,76 \mathrm{~b}, \mathrm{c}$ \\
O & $81,62 \pm 2,46 \mathrm{c}$ \\
OGAG & $98,88 \pm 3,67 \mathrm{~b}$ \\
OSC & $96,26 \pm 3,88 \mathrm{~b}, \mathrm{c}$ \\
\hline
\end{tabular}

$\mathrm{N}$ : normal; NGAG: normal tratada com precursores de glicosaminoglicanos; NSC: normal tratada com sulfato de condroitina A; O: osteoartrótica; OGAG: osteoartrótica tratada com precursores de glicosaminoglicanos; OSC: osteoartrótica tratada com sulfato de condroitina A

Letras distintas na coluna indicam diferença entre valores $(\mathrm{P}<0,05)$.
A comparação dos grupos osteoartróticos com o normal demonstrou perda celular significativa, apesar de se verificar uma atividade reparativa decorrente das lesões degenerativas da DAD.

Os grupos O, OGAG, OSC não diferiram quanto à contagem celular dos grupos OGAG, OSC. Inesperada foi a observação de que este parâmetro não diferiu entre OSC e $\mathrm{O}$, apesar das alterações degenerativas menos intensas no primeiro. $\mathrm{O}$ aspecto que contribuiu para tal resultado foi a menor exuberância de clones, com presença de condrócitos, que se apresentaram dispersos por toda matriz, com maior quantidade de matriz interterritorial, sem agrupamentos celulares na cartilagem articular do grupo OSC (Fig. 3D). Paralelamente, a menor celularidade no grupo $\mathrm{O}$, esperada e condizente com a literatura (Gomes, 2006; Gonçalves et al., 2008; Melo et al., 2008; ), deveu-se ao processo degenerativo grave, com extensa necrose de condrócitos. Dessa forma, a contagem de células não possibilitou determinar diferenças entre este grupo e o OSC, mas as alterações morfológicas variaram de intensidade e gravidade nas diferentes camadas das cartilagens. É provável que a metodologia de avaliação por camada, empregada por Gomes (2006), seja mais eficiente para evidenciar os efeitos dos fármacos sobre as cartilagens articulares tratadas.

O IP permitiu avaliar a concentração de glicosaminoglicanos. Nos grupos N, NGAG, NSC, foram observados IPs mais baixos, e que não diferiram entre si (Tab. 2). Este resultado, associado à celularidade, sugere que, embora os normais tratados (NGAG, NSC) apresentassem número reduzido de condrócitos em comparação ao normal (N), a concentração de GAG permaneceu a mesma, indicando atividade aumentada dessas células naqueles grupos (Fig. $3 \mathrm{~A}-\mathrm{C})$.

Constatou-se maior IP no grupo $\mathrm{O}$, resultado que corroborou tanto com os achados morfológicos quanto com a celularidade desse grupo. Em conjunto, essas observações caracterizaram quadro osteoartrótico mais acentuado, com menor síntese de proteoglicanos e elevado IP (Fig. 3D)

Entre grupos, os OGAG e OSC, não houve diferença significativa quanto ao IP, assim como já verificada na contagem de células (Fig. 3E-F). 


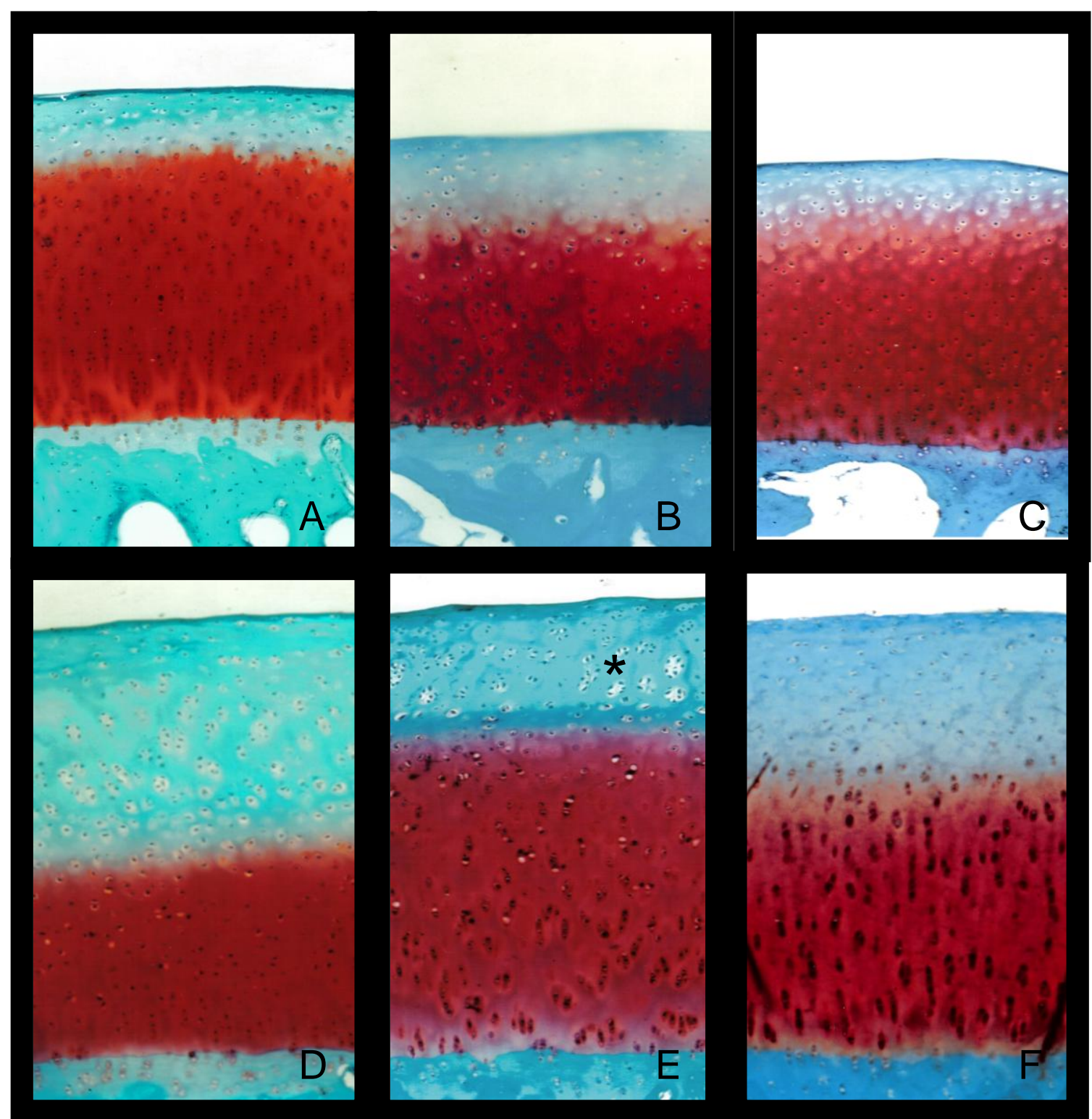

Figura 3. Fotomicrografias de cartilagens articulares de patela de cães. Safranina O-fast green. 107,1x. A) grupo normal; B) grupo normal, tratado com precursores de glicosaminoglicanos; C) grupo NSC; D-F) redução progressiva da intensidade de coloração da ME; D) grupo osteoartrótico, acentuada; E) grupo osteoartrótico, tratado com precursores de glicosaminoglicanos, moderada com formação de clones sem produção de matriz (*); F) grupo osteoartrótico, discreta.

Interessante foi o fato de mais uma vez o grupo OSC ter apresentado comportamento distinto dos demais osteoartróticos ao se assemelhar quanto à concentração de glicosaminoglicanos aos grupos $\mathrm{N}$ e NSC. Este resultado é intrigante, sendo necessário, para justificá-lo, considerar que, apesar da celularidade reduzida, os condrócitos desse grupo apresentaram-se metabolicamente ativos, aptos a manter a síntese de proteoglicanos, determinando, assim, alterações osteoartróticas menos graves. $\mathrm{O}$ sulfato de condroitina A agiu na cartilagem osteoartrótica, reduzindo a perda de proteoglicanos decorrente do processo degenerativo (Fig. 3F). Paralelamente, observou-se que o maior número de clones no grupo OGAG não foi acompanhado de aumento da síntese de proteoglicanos (Fig. $3 \mathrm{E})$. Na osteoartrose são produzidos mediadores 
diversos, com ações catabólicas, incluindo metaloproteinases, prostaglandinas, citocinas e fatores locais, dentre outros (Aigner e MacKenna, 2002; Goggs et al., 2003). Provavelmente, o sulfato de condroitina A reduziu a síntese ou a ação desses mediadores, bem como pode ter possibilitado elevado anabolismo pelos condrócitos, com maior produção de proteoglicanos ou de outras substâncias como as TIMPs ou os fatores de crescimento (IGF, TGF BMPs), importantes para a manutenção da cartilagem normal (Bali et al., 2001; Gonçalves et al., 2008; Melo et al., 2008). Achados similares aos do grupo OGAG foram obtidos por Melo et al. (2008) no emprego de ácido hialurônico na DAD, quando se observou morfologia semelhante com aumento da celularidade e do IP.

Tabela 2. Valores médios e desvios-padrão do índice de proporcionalidade aos proteoglicanos em cartilagens articulares normais e osteoartróticas de cães tratados ou não com precursores de glicosaminoglicanos e sulfato de condroitina A

\begin{tabular}{lc}
\hline Grupos & $\begin{array}{c}\text { Índice de } \\
\text { proporcionalidade }\end{array}$ \\
\hline $\mathrm{N}$ & $0,3657 \pm 0,016 \mathrm{a}, \mathrm{d}$ \\
$\mathrm{NGAG}$ & $0,2902 \pm 0,031 \mathrm{a}$ \\
$\mathrm{NSC}$ & $0,3235 \pm 0,035 \mathrm{a}, \mathrm{d}$ \\
$\mathrm{O}$ & $0,5423 \pm 0,029 \mathrm{~b}$ \\
OGAG & $0,4397 \pm 0,016 \mathrm{c}$ \\
OSC & $0,3973 \pm 0,018 \mathrm{c}, \mathrm{d}$ \\
\hline
\end{tabular}

$\mathrm{N}$ - normal; NGAG - normal tratada com precursores de glicosaminoglicanos; NSC - normal tratada com sulfato de condroitina A; O - osteoartrótica; OGAG osteoartrótica tratada com precursores de glicosaminoglicanos; OSC - osteoartrótica tratada com sulfato de condroitina A.

Letras distintas na coluna indicam diferença estatística significativa para $(\mathrm{P}<0,05)$.

Finalmente, os efeitos dos precursores de glicosaminoglicanos e do sulfato de condroitina A na cartilagem normal devem ser questionados, uma vez que foi observada redução do número de condrócitos em cartilagens normais. A avaliação isolada da cartilagem articular não permite inferir que a menor celularidade foi um efeito deletério direto dos medicamentos. Estudos sobre o efeito dos precursores de glicosaminoglicanos são controversos. Experimentos in vitro relatam a inibição da degradação da cartilagem na presença de glicosaminoglicanos (Bassleer et al., 1998), enquanto outros relatam efeitos adversos nas propriedades biomecânicas ou na viabilidade celular de explantes de cartilagem (de Mattei, 2002). As condições de cultivo, portanto, são determinantes da resposta dos condrócitos e de explantes aos glicosaminoglicanos (Mroz e Silbert, 2004; Varghese et al. 2007), o que pode explicar a variação na resposta aos tratamentos. Contudo estudos in vivo são pouco frequentes.

\section{CONCLUSÕES}

Os precursores de glicosaminoglicanos e o sulfato de condroitina A reduziram a celularidade na cartilagem articular normal, contudo não determinaram a ocorrência de alterações neste tecido, como demonstradas pelas características semelhantes à normalidade. Ambos os fármacos testados exerceram também ações na cartilagem osteoartrótica, embora apenas o sulfato de condroitina A tenha sido capaz de reduzir as lesões degenerativas e estimular o metabolismo da cartilagem.

\section{REFERÊNCIA BIBLIOGRÁFICAS}

AIGNER, T.; MACKENNA, L. Molecular pathology of osteoarthrotic cartilage. Cell. Mol. Life Sci., v.59, p.5-18, 2002.

BALI, J.P.; COUSSE, H.; NEUZIL, E. Biochemical basis of the pharmacologic action of chondroitin sulfates on the osteoarticular system. Semin. Artritis Rheum., v.31, p.58-68, 2001.

BIASI, F.; RAHAL, S.C.; VOLPI, R.S. et al. Reconstrução do ligamento cruzado cranial em cães, associado ou não ao sulfato de condroitina. Arq. Bras. Med. Vet. Zootec., v.57, p.442-447, 2005.

BASSLEER, C.; ROVATI, L.; FRANCHIMONT, P. Stimulation of proteoglycan production by glucosamine sulfate in chondrocytes isolated from human osteoarthritic articular cartilage in vitro. Osteoarth. Cartil., v.6, p.427-434, 1998.

BOBINAC, D.; SPANJOL, J.; ZORICIC, S. et al. Changes in articular cartilage and subchondral bone histomorphometry in osteoarthritic knee joints in humans. Bone, v.32, p.284-290, 2003.

de MATTEI, M.; PELLATI, A.; PASSELO, M. et al. High doses of glucosamine- $\mathrm{HCl}$ have detrimental effects on bovine articular cartilage explants cultured in vitro. Osteoarth. Cartil., v.10, p.816-825, 2002. 
FENTON, J.I.; CHLEBEK-BROWN, K.A.; PETERS, T.L. et al. The effects of glucosamine derivatives on equine articular cartilage degradation in explant culture. Osteoarth. Cartil., v.8, p.444-451, 2000a.

FENTON, J.I.; CHLEBEK-BROWN, K.A.; PETERS, T.L. et al. Glucosamine $\mathrm{HCl}$ reduces equine articular cartilage degradation in explant culture. Osteoarth. Cartil., v.8, p.258-265, 2000b.

FERNANDES, J.C.; JAVANOVIC, D.; DEHNADE, F. et al. Resection of the anterior cruciate ligament of the knee using arthroscopy induces arthrosis in dogs. Validity of the Pond-Nuki model. Ann. Chir., v.52, p.768-775, 1998 .

GANNON, F.H.; SEKOLOFF, L. Histomorphometry of the aging human patella: histologic criteria and controls. Osteoarth. Cartil., v.7, p.173-181, 1999.

GLASSON, S.S.; BLANCHET, T.J.; MORRIS, E.A. The surgical destabilization of the medial meniscus (DMM) model of osteoarthritis in the $129 / \mathrm{SvEv}$ mouse. Osteoarth. Cartil., v.15, p.1061-1069, 2007.

GOLDRING, M.B. Update on the biology of the chondrocyte and new approaches to treating cartilage diseases. Best Pract. Res. Clin. Rheumatol., v.20, p.1003-1025, 2006.

GOMES, M.G. Efeitos do sulfato de condroitina e do hialuronato de sódio na histomorfometria da cartilagem articular de cães com osteoartrose experimental. 2006. 71f. Dissertação (Mestrado) Instituto de Ciências Biológicas, Universidade Federal de Minas Gerais, Belo Horizonte.

GONÇALVES, G.; MELO, E.G.; GOMES, M.G. et el. Effects of chondroitin sulfate and sodium hyaluronate on chondrocytes and extracellular matrix of articular cartilage in dogs with joint disease. Arq. Bras. Med. Vet. Zootec., v.60, p.93-102, 2008.

GOGGS, R.; CARTER, S.D.; SCHULE-TANZIL, G. et al. Apoptosis and the loss of chondrocytes survival signals contribute to articular cartilage degradation in osteoarthritis. Vet. J., v.166, p.140-158, 2003.

HERZOG, W.; LONGINO, D. The role of muscles in joint degeneration and osteoarthritis. J. Biomech., v.40, p.S54-S63, 2007.

JUNQUEIRA, L.C.; CARNEIRO, J. Tecido cartilaginoso. In: JUNQUEIRA, L.C.; CARNEIRO, J. (Eds). Histologia Básica. Rio de Janeiro: Guanabara Koogan,1999. p.101-107.

KLEEMAN, R.U.; KROCKER, D.U.; CEDRARO, A. et al. Altered cartilage mechanics and histology in knee osteoarthritis: relation to clinical assessment (ICRS Grade). Osteoarth. Cartil., v.13, p.958-963, 2005.
LAADHAR, L.; ZITOUNI, M.; KALLE-SELLAMI, M. et al. Physiopathologie de l'arthrose. Du cartilage normal au cartilage arthrosique: facteurs de prédisposition et mécanismes inflammatoires. Rev. Med. Intern., v.28, p.531-536, 2007.

LORENZ, H.; RICHTER, W. Osteoarthritis: Cellular and molecular changes in degenerating cartilage. Prog. Histochem. Cytochem., v.40, p.135-163, 2006.

MARIJNISSEN, A.C.A.; VAN ROERMUND, P.M.; TEKOPPELE, J.M. et al. The canine 'groove' model, compared with the ACLT model of osteoarthritis. Osteoarth. Cartil., v,10, p.145-155, 2002.

MELO, E.G.; NUNES, V.A.; REZENDE, C.M.F. et al. Sulfato de condroitina e hialuronato de sódio no tratamento da doença articular degenerativa em cães. Estudo histológico da cartilagem articular e membrana sinovial. Arq. Bras. Med. Vet. Zootec., v.60, p.83-92, 2008.

MROZ, P.J.; SILBERT J.E. Use of 3H-glucosamine and 35 Ssulfate with cultured human chondrocytes to determine the effect of glucosamine concentration on formation of chondroitin sulfate. Arthr. Rheum., v.50, p.3574-3579, 2004

PRITZKER, K.P.H.; GAY, S.; JIMENEZ, S.A. et al. Osteoarthritis cartilage histopathology: grading and staging. Osteoarth. Cartil., v.14, p.13-29, 2006.

ROMANO, L.; PEREIRA, C.A.M.; SCHAMAEDECKE, A. Análise biomecânica do joelho íntegro e com ruptura do ligamento cruzado cranial quanto ao grau de deslocamento cranial e rigidez articular em cães. Acta Cirurg. Bras., v.21, p.46-50, 2006

SCHWALDER, P. Eigene methoden zur operativen rekonstruktion bei rupture des vorderen und hinteren kreuzbandes. Kleinterpraxis, v.7, p.323-330, 1989.

SIMON, T.M.; JACKSON, D.W. Articular Cartilage: Injury Pathways and Treatment Options. Sports Med. Arth. Rev., v.14, p.146-154, 2006.

VARGHESE, S.; THEPRUNGSIRIKUL, P.; SAHANI, S. et al. Glucosamine modulates chondrocyte proliferation, matrix synthesis and gene expression. Osteoarth. Cartil., v.15, p.59-68, 2007.

YUAN, G.-H.; TANAKA, M.; MASUKOHONGO,K. et al. Characterization of cells from pannus-like tissue over articular cartilage of advanced osteoarthritis. Osteoarth. Cartil., v.12, p.38-45, 2004. 